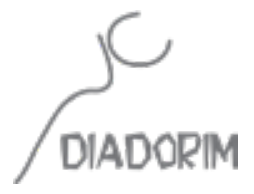

\title{
LEARNING POVERTY AMONG PRIMARY SCHOOL PUPILS: A CASE STUDY OF NATIVE (TELUGU) AND ENGLISH MEDIUM SCHOOLS OF ANDHRA PRADESH, INDIA
}

\author{
Selvaraj Arulmozi ${ }^{1} \&$ Mendem Bapuji ${ }^{2}$
}

\begin{abstract}
Learning poverty is one of the major issues that has come into focus recently in India, especially in Andhra Pradesh. According to the World Bank (2019), learning poverty is the inability to read and comprehending a simple story or paragraph in a given language. It is applicable to all disciplines i.e. either in humanities or in mathematics and sciences. This inability is found especially among students aged between 5-10 (at the end of the primary school). In the present paper, we highlight what the driving forces behind this learning poverty are as well as which can be taken into consideration to curb it. This paper is an attempt to present the problem of learning poverty prevalent in Telugu and English medium schools of Andhra Pradesh, India. However, no remedies have been suggested, as it is very nascent to offer any such suggestions without understanding the nature of learning poverty in this particular scenario. In that way, this paper is only an endeavour to contextualize learning poverty and put forward a blueprint for future conduct of research in this area.
\end{abstract}

Keywords: Learning Poverty, Reading and Comprehension, Telugu Medium, English Medium and School Children

1 Associate Professor - Centre for Applied Linguistics \& Translation Studies - University of Hyderabad / Cátedra UNESCO "Políticas Linguísticas para o Multilinguismo" (UNESCO Chair "Language Policies for Multilingualism")

2 Guest faculty - Centre for Applied Linguistics \& Translation Studies - University of Hyderabad 


\section{Introduction}

According to Jawaharlal Nehru (as quoted in the Times of India, 2019) "The children of today will make the India of tomorrow. The way we bring them up will determine the future of the country". The remarks were made on November 14, which is Children's Day in India. Jawaharlal Nehru who was keen on the development and education of children remarked that the children who become tomorrow's citizens should be equipped with proper educational skills because they will be the torchbearers in the overall development of the country.

The way one trains a child in primary education determines the future of the country. Imparting the right kind of education at primary level with good reading, writing and comprehension skills equips the child with all the necessary skills at, which will be helpful to their future education and advanced studies. Equipping children with good reading, writing and comprehension skills ultimately helps them to become knowledgeable citizens of the country. The overall development of their personalities and the upright values necessary for the society will become the essential qualities of these subjects. When they grow up they will be unselfish human beings in society. Education is one of the main points in the country's Sustainable Development Goals (SDGs) proposed by the United Nations Organization (UNO) in 2012. In the present educational scenario, today's children in primary education are prone to learning poverty. "Eliminating learning poverty is as important as eliminating extreme monetary poverty, stunting, or hunger" (World Bank, 2019:6). Considering the grave situation, it becomes necessary to bring into the light the problem of learning poverty on various platforms, especially in academia and in the evaluation of public policies.

\section{Education System in Andhra Pradesh}

Primary education is one of the major aspects which lays the foundation for the overall development of a child upon whom the future development of the country is built. In the last fourteen years, the budget allocation for education has been increased by the Central and State governments of India. "Budget 2020 has increased the allocation for the education sector by 5 percent to Rs 99,311.52 crore in FY21. Of this, the department of higher education has been allocated Rs 39,466.52 crore while the school education and literacy department was given Rs 59,845 crore" ("Budget 2020: Education Sector Allocation up 5\%"). There are 61,128 schools with a total strength of 7,041,568 students. These schools were spread across 13 districts in the state and they are classified as urban, rural and residential schools. The school education department of the state has further categorized the schools into Municipal, Residential, Social Welfare, Zilla Praja Parishad (ZPP), Aided and Unaided for administrative purposes. Further, on the basis of medium of instruction two types of schools have emerged, viz. English medium schools and non-English medium schools (regional languages are used for instruction). According to the Seventh All India School Education Survey (2006), the number of schools in

Diadorim, Rio de Janeiro, vol. 22, número 1, p. 187-199, 2020. 
rural, urban regions of the Andhra Pradesh state is presented below: (Read LB - Local Body, PA- Private Aided, UPA-Private UnAdided).

Number of Primary Schools in Andhra Pradesh

\begin{tabular}{|c|c|c|c|c|c|c|c|c|c|c|}
\hline \multirow[b]{2}{*}{$\begin{array}{l}\text { S. } \\
\text { No }\end{array}$} & \multirow[b]{2}{*}{ State } & \multirow[b]{2}{*}{ Area } & \multirow{2}{*}{$\begin{array}{c}\text { Total } \\
\text { Number } \\
\text { of } \\
\text { Schools }\end{array}$} & \multicolumn{7}{|c|}{ School Type } \\
\hline & & & & $\begin{array}{l}\text { Only } \\
\text { Boys }\end{array}$ & $\begin{array}{l}\text { Only } \\
\text { Girls }\end{array}$ & Co-ed/ & Government & LB & PA & UPA \\
\hline 1 & 2 & 3 & 4 & 5 & 6 & 7 & 8 & 9 & 10 & 11 \\
\hline \multirow{3}{*}{1} & \multirow{3}{*}{$\begin{array}{l}\text { Andhra } \\
\text { Pradesh }\end{array}$} & Rural & 53,883 & 267 & 614 & 53002 & 4380 & 46803 & 1468 & 1232 \\
\hline & & Urban & 7245 & 62 & 246 & 6937 & 1106 & 2970 & 814 & 2355 \\
\hline & & Total & 61,128 & 329 & 860 & 59,939 & 5,486 & 49,773 & 2,282 & 3,587 \\
\hline
\end{tabular}

Seventh all India School Educational Survey, NCERT, New Delhi, 2006

Number of All Schools in Andhra Pradesh

\begin{tabular}{|c|c|c|c|c|c|c|c|c|c|c|}
\hline \multirow[b]{2}{*}{$\begin{array}{l}\text { S. } \\
\text { No }\end{array}$} & \multirow{2}{*}{ State } & \multirow{2}{*}{ Area } & \multirow{2}{*}{$\begin{array}{c}\text { Total } \\
\text { Number } \\
\text { of } \\
\text { Schools }\end{array}$} & \multicolumn{7}{|c|}{ School Type } \\
\hline & & & & $\begin{array}{l}\text { Only } \\
\text { Boys }\end{array}$ & $\begin{array}{l}\text { Only } \\
\text { Girls }\end{array}$ & Co-ed & Government & LB & PA & UPA \\
\hline 1 & 2 & 3 & 4 & 5 & 6 & 7 & 8 & 9 & 10 & 11 \\
\hline \multirow{3}{*}{1} & \multirow{3}{*}{$\begin{array}{l}\text { Andhra } \\
\text { Pradesh }\end{array}$} & Rural & 75428 & 766 & 1282 & 73380 & 5934 & 62658 & 2019 & 4817 \\
\hline & & Urban & 15,869 & 328 & 953 & 14,588 & 2,141 & 4,180 & 1,895 & 7,653 \\
\hline & & Total & 91297 & 1094 & 2,235 & 87,968 & 8,075 & 66,838 & 3,914 & 12,470 \\
\hline
\end{tabular}

Seventh all India School Educational Survey, NCERT, New Delhi, 2006

\section{Learning Poverty}

Learning Poverty is defined as the percentage of 10-year-olds who cannot read and understand a simple story (World Bank, 2019). Learning poverty means being unable to read and understand a simple text by age 10 . This indicator brings together schooling and learning indicators: it begins with the share of children who haven't achieved minimum reading proficiency (as measured in schools) and is adjusted by the proportion of children who are out of school (and are assumed not able to read proficiently).

Further, addressing the issue of learning poverty, the World Bank 2019 report in collaboration with UNESCO remarks that "reading is a gateway for learning as the child progresses through school and conversely, an inability to read slams that gate shut". Reading inability is often found among uneducated people but in cases where learning poverty is present, we observe it in the children aged 5-11 undergoing primary education. Even though they are admitted into schools, their proficiency in reading remains poor which translates into a major proportion of the children not acquiring the fundamental skill, i.e. reading. 
Learning poverty rates are especially high in developing countries like India which rely on their own population as human capital for skills, knowledge, and experience possessed. This certainly has an effect (directly or indirectly) in achieving the long-term goals listed in the Sustainable Development Goals (SDG) of respective countries. Reading will always have a cumulative effect on subsequent skills such as comprehending and understanding. If those fail in primary education, they will not flourish in later education and will finally become a hindrance in the workforce. This problem also undermines and destabilizes sustainable growth and poverty reduction. Poor education outcomes will always affect or have major costs for future prosperity of a country.

Reading inability always has a snowball effect on subsequent skills such as comprehending and understanding. Those who fail in primary education will not flourish in later levels of education and will eventually become a part of an unskilled workforce group. Nowadays as the demand for a skilled workforce is growing unskilled workers will be laid off resulting in mass unemployment. The problem of learning poverty also undermines and destabilizes sustainable growth and hinders the process of poverty reduction. Prosperity of a country gets badly affected if the problem of learning poverty is not addressed in an earlier stage. In this statement, it is all evident that a country's prosperity is directly related to the education policies of that country.

\section{Earlier Works on Learning Poverty}

The initial study on learning poverty was carried out by the World Bank in collaboration with UNESCO (World Bank, 2019). By considering various case studies, it highlights the problems of learning poverty and the crisis it brings in the workforce. The study also highlights that developing countries are the most vulnerable to learning poverty. Ingrum (2006:76) discusses the situation of school dropouts due to poverty and learning disabilities. In the study the author argues that the "lower Socio Economic Status (SES) increases the probability of dropping out of high school, learning disabilities increase the probability of dropping out of high school and the interaction between lower socio economic status (SES) and learning disabilities further increases the probability of dropping out of high school" (ibid). Finally, the study suggests that students facing learning disabilities should be given more encouragement in order to complete their primary and high school education. The study also suggests that identifying the characteristic features of learning disabilities and informing them to teachers and parents will help the children to attain overall success in primary and high school education.

Some Indian national newspapers (such as Times of India, Hindustan Times, Deccan Chronicle, etc.) have also brought out articles (both in print and e-paper versions) about learning poverty. On November 22, 2018, Times of India published an article written by Rudroneel Ghosh titled "Failing Schools: With poor quality of learning, Indian students aren't being equipped for jobs of the future". The article states that Indian teachers have a high degree of 
commitment for making the students crack exams but not for delivering quality education. The entire teaching experience does not focus on quality learning. The article goes on to say that reports that "performance in exams became the ultimate criteria irrespective of the quality of learning which lays a strong foundation in the basics of each subject the children opted". Finally, the author suggests improving the quality in teaching. Another article dated, $16^{\text {th }}$ November, 2019 with the title "Read it Right: fixing the learning poverty to tackle actual poverty". The article affirms that "According to the Annual Status of Education Report (ASER) report 2018, only $50.3 \%$ of Class V children can't read a Class II level text. This shows a high degree of what the World Bank defines as learning poverty - being unable to read and understand a simple age-appropriate text by age 10". If a child is unable to read a text appropriate for their age, the grasping power diminishes negatively affecting later schooling. Finally, the article suggests that India must focus on the foundational learning and age appropriate reading by class III under the new educational policy.

Similarly, the Hindustan Times dated, October 13 ${ }^{\text {th }}, 2019$ published an article titled “India's students have poor learning levels. Can foundational education help them?", written by KumKum Dasgupta. In the article, the author criticizes the fact that the media could not highlight one of the main points proposed by National Educational Policy (NEP), i.e. foundational learning. According to the author "foundational learning is the ability to read with meaning and do basic math calculations by class 3". According to the NEP policy, pre-primary and grades 1 and 2 are considered as foundational stages which lay the basis for all learning that follows. The policy also envisioned that the country should achieve foundational skills viz. reading, writing and arithmetic in the primary school children by 2025. According to Dhawan (2018:3) Foundational learning skills, i.e., reading with comprehension and being able to do simple math calculations by class 3 , is important because students who do not achieve them find it difficult to catch up later. Class 3 is a key inflection point when children are expected to "read to learn", and this is where children who have not made it essentially get left behind (ibid).

\section{Methodology}

For studying the learning poverty in Andhra Pradesh, the researchers first conducted a pilot study in Krishna and Guntur districts of Andhra Pradesh. The reason for selecting the two districts is that they are educationally well ahead with children coming from both rural and urban backgrounds. After the pilot study, two schools were shortlisted viz. Zilla Praja Parishad High School (ZPPHS) from Velagapudi Village (rural) Guntur district and Atkins High School (AHS) from Vijayawada (urban) Krishna district of Andhra Pradesh. Both boys and girls aged 5-10 were taken as participants. All subjects are from different socioeconomic backgrounds. Zilla Praja Parishad High School (ZPPH) is Telugu medium and Atkins High school (AHS) is an English medium school. Parent's feedback was also taken into consideration for correlating the problems of learning that lead to learning poverty. The research was conducted in December 2019. Qualitative analysis is applied and the results were interpreted on the basis the facts 
obtained and parent's opinions were considered to cross check and validate the reliability of data collected.

\section{Research Tools}

Articles for reading from the subjects own texts and written samples from the subjects answer scripts have been used as research tools to identify learning poverty in the sample.

\section{Errors (reading \& writing) as markers for identifying learning poverty}

The working definition of errors in both the languages either in Telugu or in English only entails spelling mistakes and mispronunciation in this paper. However, errors categorized by pioneers such as Pit Corder, Larry Selinker, Carl James and others in the area do not come under the purview of this research paper, as researcher is only concerned about some special errors, which can function as markers of identifying learning poverty to a certain extent.

\section{Identification of Learning Poverty through a Reading Activity in Both Telugu and English Medium Schools}

In the present research, participants were handed over articles for reading as an activity to measure their reading skills. The sample size was 64 and the sample was selected in such a way that there are a set 16 pupils for both $5^{\text {th }}$ and $3^{\text {rd }}$ class each set. Total participants in $5^{\text {th }}$ class are 32 where 16 pupils belong to Telugu medium and the other 16 belong to English medium. Similarly, there are 32 pupils in $3^{\text {rd }}$ class where 16 are from Telugu medium background and the other 16 belong English medium.

It becomes necessary here how Telugu medium and English medium syllabi are designed in Andhra Pradesh state to put the research in perspective. Telugu medium students have English as one of the compulsory subjects along with other subject books, which are in Telugu script. English medium students have Telugu as one of the compulsory subjects where all the subject books are in English. All the subjects (pupils) were supposed to read both Telugu and English articles. Each article has words ranging between 400-500. As a condition, $5^{\text {th }}$ class students were made to read both Telugu and English articles from $3^{\text {rd }}$ class and the $3^{\text {rd }}$ class students were made both Telugu and English articles from $2^{\text {nd }}$ class syllabus.

During the analysis of the reading activity, it was found out that the students belonging to $5^{\text {th }}$ class Telugu medium were able to read Telugu articles with reasonable proficiency whereas their English article reading was deficient. They could not pronounce most of the vocabulary properly and the right tone was completely missing. The results of Telugu medium students from $3^{\text {rd }}$ class were not any different from the above $5^{\text {th }}$ class Telugu medium students results. 
In the case of English medium students from $5^{\text {th }}$ class the analysis shows that they could not read either English or Telugu articles with acceptable proficiency. Similarly, $3^{\text {rd }}$ class English medium students too failed to perform in both English and Telugu article reading.

In order to understand the issue of lack of proper reading skills among the samples, the researchers reached out to some of the available parents of the participants. During some discussions with parents of almost all the participants have provided deep insights into how they feel about education from their outlook. The opinions expressed were given below.

1. Around 13 parents who were illiterate could not offer any kind of home schooling or mentoring to help with their kids in homework.

2. Around 11 parents did not have time to spend with their kids to offer any help with their education even though they were educated. This was because the parents themselves were locked up most of the time in their professional careers.

3. Around 14 parents who were below the poverty line category and could not afford decent education to their children. However, these parents dreaming of a prospective future for their kids ventured out to borrow money and spend it on expensive English medium schools. The intention of the parents might be good but it cannot be denied that the role of comparison with well-off families was missing. Such borrowing burdened them with financial stress adding to their woes.

4. Some of the parents even expressed that their kids were deprived of fully functional mother tongue acquisition due to the intermittent interference of a foreign language like English. This statement may appear to be completely out of place at the first look but it will offer some under researched area of linguistics and it will offer some valid points to the under researched area of interlanguage linguistics.

A fine and justifying balance is necessary while offering courses in dual languages. To conclude, various factors like socio, cultural, educational and economic contribute to learning poverty among the Telugu and English medium school pupils of Andhra Pradesh.

\section{Identification of Learning Poverty through Answer Scripts in both English and Telugu from English Medium School}

Based on the results of the reading test, the researchers also proceeded to analyse whether the low proficiency levels of reading among children has any relation in writing proficiency. In order to do this the researchers used the answer scripts and written notes of selected students, to verify if the error patterns in writing are reflections of reading inability. The following pictures are taken from the answer scripts of some of the participants from Atkins English medium High 
School:

Figure 1: A third class student' answer Script written in Telugu

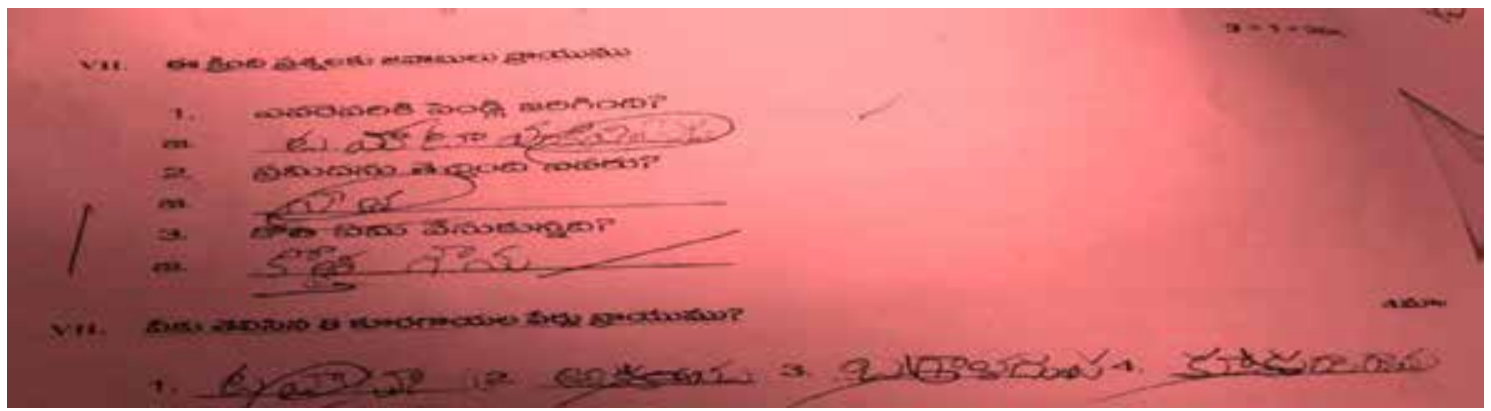

Explanation Table for Fig.1 Names of Vegetables, Proper Names and Objects:

\begin{tabular}{|llllll|}
\hline \multicolumn{2}{|l}{ Actual word Phonetic script } & \multicolumn{2}{l}{ Written word/Phonetic Script } & Gloss \\
టమాట & [tama:ta] & $\rightarrow$ & టమటా & [tamta] & 'tomato' \\
వంకాయ & [vankaja] & $\rightarrow$ & వంకినిపండ & [vankinipanda] & 'brinjal \\
సీత & [sita] & $\rightarrow$ & సీత & [neeta] & 'Sita' (propername' \\
కొత్త గౌను & [kotta gaunu] & $\rightarrow$ & కొతై గౌను & [kotta gaunu] & 'new frock' \\
టమాట & [tama:ta] & $\rightarrow$ & టవాట & [tama:ta] & 'tomato' \\
\hline
\end{tabular}

Figure 2: A third class student' answer Scripts of number written in Telugu

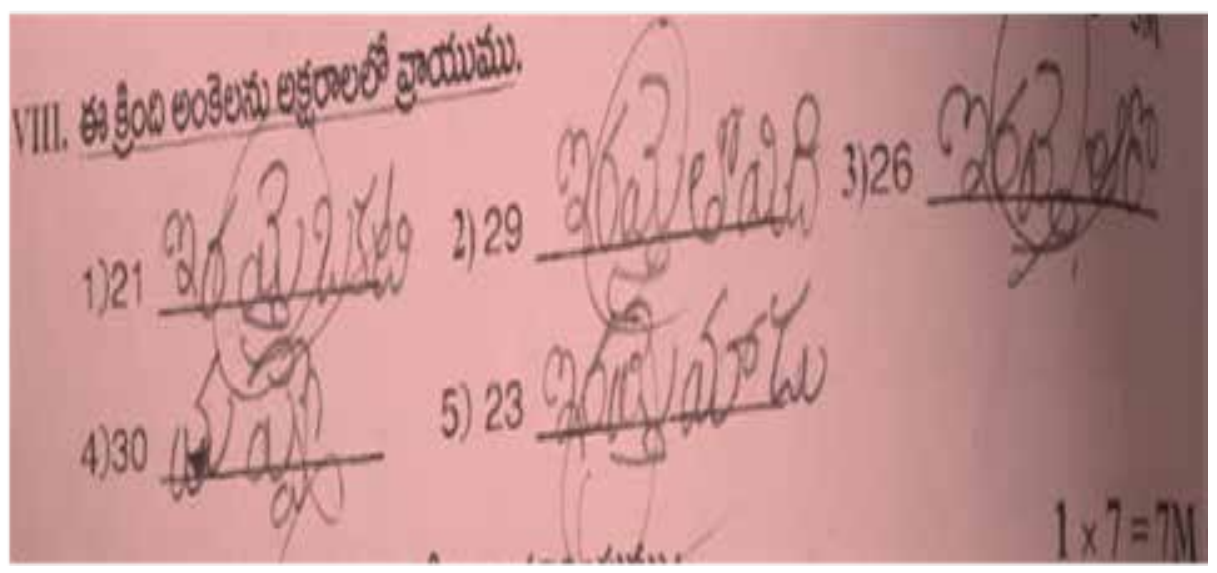

Explanation Table for Fig. 2: Numerals:

\begin{tabular}{|lcccc|}
\hline Actual word Phonetic script & Written word & Phonetic Script & Gloss \\
ఇరవైతొమ్మిది & [iravai $\theta 0 m m i ð i]$ & $\rightarrow$ ఇరమైతొవింది & [iravai $\theta$ oviði] & 'twenty nine' \\
ఇరవైఒకటి & [irravaiokati] & $\rightarrow$ ఇరమైఒకటి & [irramaiokati] & 'twenty one' \\
ముఫై $\quad[$ tama:ta] & $\rightarrow$ ముపీs & [tama:ta] & 'thirty' \\
\hline
\end{tabular}


Picture 3: A third class student' answer Scripts written in English

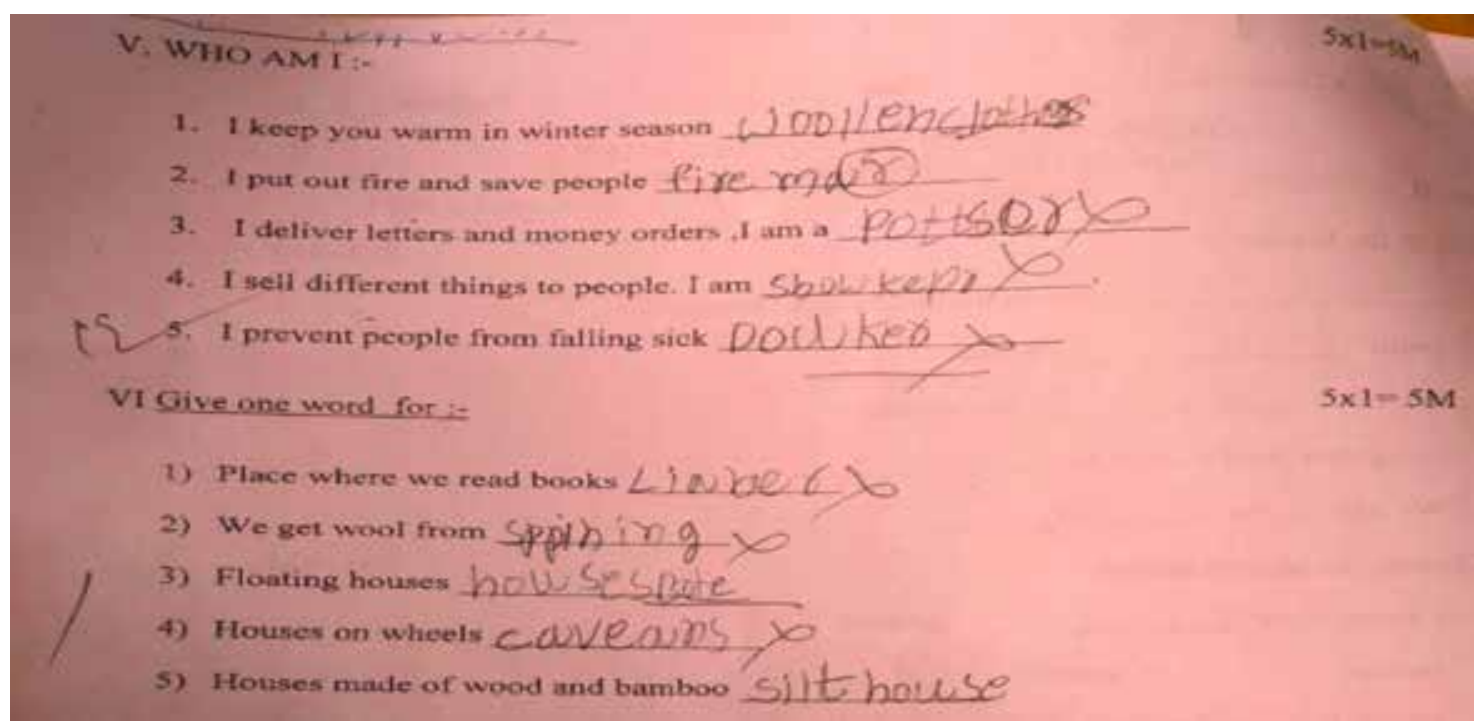

Explanation Table for Fig. 3 -A few of English Words from the Written Test:

\begin{tabular}{|c|c|c|c|c|}
\hline S.No & \multicolumn{2}{|c|}{ English: Question No.5 } & \multicolumn{2}{c|}{ English: Question No.6 } \\
\hline 1 & Post man & pottSer & Library & Linber \\
\hline 2 & Shop keeper & show kepr & Spinning & Sppining \\
\hline 3 & Doctor & Doctker & Hose boat & housesBote \\
\hline 4 & Fireman & fire mar & Carriages & Caveans \\
\hline
\end{tabular}

\section{Discussion on Learning Poverty on English Medium Schools}

The above are some of the examples taken from the answer scripts written by the third class students. The answer scripts were taken from English as well as Telugu for the analysis. All these spelling mistakes can be attributed at least partially to their reading mistakes.

In figure 1, Telugu words mentioned above reflect the reading of the children from the Atkins English medium high school. In the written scripts of the children of the third class students, many of the errors belong to categories such as spelling mistakes, unnecessary inclusion of extra letters and unnecessary agglutination. Along with the proper and common nouns in figure 1, the children made errors in the writing of Telugu numerals too in figure 2.

In the above errors of reading and writing, rural students who attend school situated in a city have committed a higher number of errors compared to the urban students in Telugu and English. These children belong to various socio-economic backgrounds. The arguments of some parents that the hindrance effects of foreign language interference while learning one's mother tongue can help us understand things if there is any such thing in terms of semilingualism. However, this does not have a scientific basis and such opinions can only considered as a possible hindrance in some cases. Moreover, if a kid is facing any such problem there are more things to be considered which have to do with learning difficulties in general or other related issues. 
This also made the researchers to think in terms of the semilingualism. Hansegard introduced the concept of semilingualism in the 1960s to describe the linguistic difficulties in Finnish immigrants experienced in Sweden. Hansegard defined semilingualism as a "half-knowledge" of the second language coupled with "half knowledge" of the first language (Hansegard 1962, 1968, quoted in Skutnabb-Kangas 1984: 250). The concept of semilingualism has also often been linked to subtractive bilingualism, in which the second language, the language of the majority, replaces the first language, that of the minority. (Lucchini, 2009). Since this paper's intention is only to present the problem of learning poverty as it is in the said society, it does not consider semilingualism as a concept related to the current research problem.

\section{Discussion on Learning Poverty on Telugu Medium Schools}

In the Telugu medium primary school, children from various socio-economic backgrounds have problems in reading and writing a simple English text. All children make mistakes in reading and writing irrespective of their socio-economic status. The following figure from the third class student's notebook reveals that Telugu medium children are unable to produce simple words that are given for homework. As it is the practice in primary schools to check the accuracy of spelling of the students as a mark of proficiency, the following picture is an example of how some reading problems can translate into written mistakes. The student might have completely understood the concepts of these words in the list below. However, it seems the student is not able to read properly and hence such improper reading may be seen as manifesting in writing.

Figure 4: English notebook picture from the $3^{\text {rd }}$ class

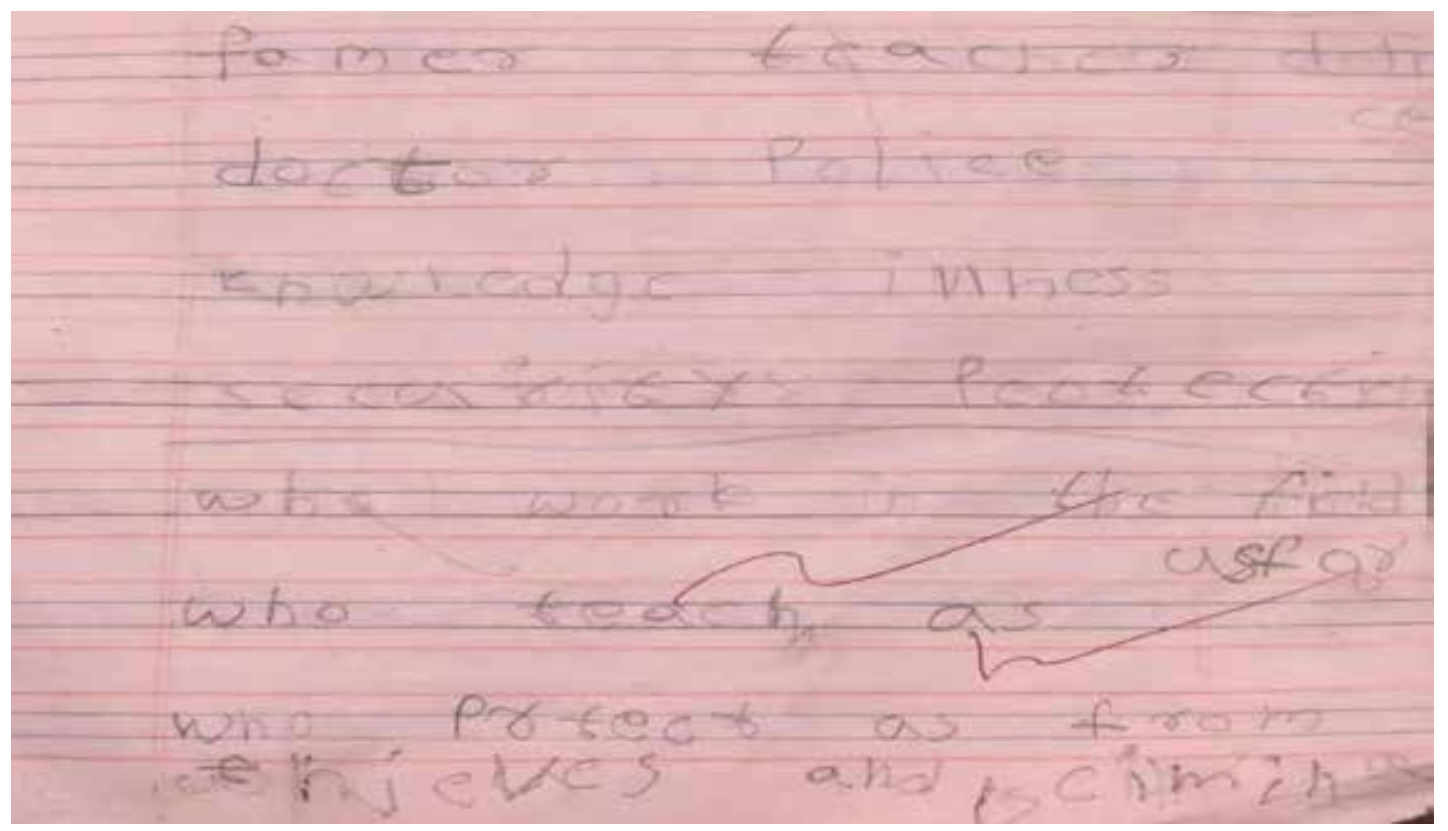

The following are the errors from the written document from a third class student's note book. 


\begin{tabular}{|ll|l|l|l|}
\hline Actual word & Written word & Actual word & Written word \\
\hline farmer & $\rightarrow$ & famer & knowledge & $\rightarrow$ knwledge \\
\hline protector & $\rightarrow$ & prtecr & us & $\rightarrow$ as \\
\hline thieves & $\rightarrow$ & hjeves & coming & $\rightarrow$ ciming \\
\hline
\end{tabular}

\section{Conclusion}

As discussed in the previous sections, learning poverty is present both in the schools of Telugu and the local English medium schools. Compared to the English medium students, Telugu medium students have moderate performance in mother tongue reading and writing but not in English language. Regarding the English language in both English medium and Telugu medium schools, learning poverty is high and may be related to diverse factors such as social, cultural, economic and educational aspects. If these are addressed properly, their learning poverty might be reduced to some extent. But we should remind ourselves we are nowhere near to solve the problem altogether:

\footnotetext{
"The new data show that $53 \%$ of all children in low- and middle-income countries suffer from learning poverty. And progress in reducing learning poverty is far too slow to meet the aspirations laid out in SDG4 - to ensure inclusive and equitable quality education. At the current rate of improvement, in 2030 about $43 \%$ of children will still be learning-poor. If countries reduce learning poverty at the fastest rates we have seen so far in this century, the global rate of learning poverty would drop to $28 \%$." (World Bank, 2019)
}

This study is our first effort on the topic of learning poverty, which we plan on extending further to include all types of schools, viz. government, non-government rural, urban, model, welfare and municipality schools of Andhra Pradesh for the correlation and cross section of the present research.

\section{References}

BUDGET 2020: Education Sector Allocation up 5\%. Moneycontrol, www.moneycontrol. com/news/business/economy/budget-2020-education-sector-allocation-up-5-4892771.html. Accessed 18 May 2020.

DHAWAN, Ashish. Connecting the Dots: Annual Report 2018. New Delhi: Central Square Foundation.

FAILING Schools: With poor quality of learning, Indian students aren't being equipped for jobs of the future. Retrieved from https://timesofindia.indiatimes.com/blogs/talkingturkey/failingschools-with-poor-quality-of-learning-indian-students-arent-being-equipped-for-jobs-of-thefuture/

HARBERT, W., et al. Language and Poverty. Bristol: Multilingual Matters, 2009. 
INDIA'S students have poor learning levels. Can foundational education help them? Retrieved from https://www.hindustantimes.com/analysis/india-s-students-have-poor-learning-levels-canfoundational-education-help-them/story-7g7N9eCXPBzh31FWjTAaRO.html

INGRUM, Adreinne. High School Dropout Determinants: The Effect of Poverty and Learning Disabilities, The Park Place Economist, Vol.14, 2006.

JAMES, Carl. Errors in Language Learning and Use: Exploring Error Analysis. London: Longman. ISBN 0582 25763-8, 1998.

LUCCHINI, Silvia. "Semilingualism: A Concept to Be Revived For A New Linguistic Policy?" Linguistic Identities, Language Shift and Language Policy in Europe, Jan. 2009, pp. 61-71, www.researchgate.net/publication/305387850_Semilingualism_A_Concept_to_be_Revived_ for_a_New_Linguistic_Policy.

MILNER, R. H. Analyzing Poverty, Learning and Teaching through a Critical Race Theory Lens, Research Review in Education, Vol.37:1: 1-53, 2013.

MINISTRY of Human Resources Development, 2019. Draft National Educational Policy 2019. MHRD, Government of India.

MORENO-DODSON, B. (ed.). Reducing Poverty on a Global Scale: Learning and Innovative Development. Washington, DC: World Bank, 2005.

NEHRU, Jawaharlal. “Children's Day India 2019: Here Are 5 Interesting Speech Ideas - Times of India." The Times of India, timesofindia.indiatimes.com/life-style/parenting/ moments/childrens-day-speech-here-are-5-interesting-speech-ideas-for-childrens-day-2019/ articleshow/72040745.cms. Accessed 16 May 2020.

READ it right: Fix learning poverty to tackle actual poverty. Retrieved from https://timesofindia. indiatimes.com/blogs/toi-editorials/read-it-right-fix-learning-poverty-to-tackle-actual-poverty/

RUDRONEEL Ghosh. "Failing Schools: With Poor Quality of Learning, Indian Students Aren't Being Equipped for Jobs of the Future." Times of India Blog, 22 Nov. 2018, timesofindia. indiatimes.com/blogs/talkingturkey/failing-schools-with-poor-quality-of-learning-indianstudents-arent-being-equipped-for-jobs-of-the-future

SCHOOL Education. AP State Portal. Retrieved on $14^{\text {th }}$ June, 2019. Retrieved from: https:// en.wikipedia.org/wiki/Education_in_Andhra_Pradesh.

SEVENTH all India School Education Survey. National Tables On Schools, Physical And Ancillary Facilities, 2006. Retrieved http://www.ncert.nic.in/programmes/education_survey/ pdfs/Schools_Physical_Ancillary_Facilities.pdf.

SINGH, B. D. R. M. Life Skills in India: An overview of evidence and current practices in our Current Education System. New Delhi: Central Square Foundation, 2015. 
SKUTNABB-KANGAS, T. Bilingualism or Not: The Education of Minorities. Bristol: Multilingual Matters, 1984.

UNESCO Institute of Statistics. "Learning Poverty - Global Alliance to Monitor Learning.", gaml.uis.unesco.org/learning-poverty. Accessed 16 May 2020.

WAPULA, R.; CHAWAWA, M. Lifelong Learning for Poverty Eradication. Singapore: Springer, 2015.

WILliAMS, F. (ed.). Language and Poverty: Perspectives on a Theme. New York: Academic Press, 1970.

WORLD BANK. Ending Learning Poverty: What Will It Take? Washington, DC: World Bank, 2019. https://open-knowledge.worldbank.org/handle/10986/32553. License: CC BY 3.0 IGO.

WORLD BANK. Learning Poverty. 2019, www.worldbank.org/en/topic/education/brief/ learning-poverty.

WORLD BANK. "Ending Learning Poverty: A Target to Galvanize Action on Literacy." www.worldbank.org/en/news/immersive-story/2019/11/06/a-learning-target-for-a-learningrevolution. Accessed 18 May 2020. 